\title{
Analysis on the Influence Factors of College Students' Consuming Trust under the Background of Mobile E-commerce
}

\author{
Jingxian Xu \\ TSL School of Business and Information Technology, Quanzhou Normal University, Quanzhou, \\ 362000, China \\ yjsxjx@126.com
}

Keywords: Mobile e-commerce, College students, Influence factors, Trust.

\begin{abstract}
With the continuous development of network technology, more and more people are fond of shopping online, the popularity rate of shopping online with the mobile devices is also increasing. However, consumers' trust has become one of the main factors hindering the mobile e-commerce development. In this paper, based on the college students consumers, the main influence factors of consuming trust of college students are analyzed in detail under the background of the mobile e-commerce. Accordingly, some solutions to how to promote consumers' confidence in the mobile e-commerce and help to develop Chinese mobile e-commerce industry, which are propounded.
\end{abstract}

\section{Development of Mobile E -commerce}

With the development of China's Internet, Chinese Mobile e-commerce is rapidly rising. China Electronic Commerce Research Center (100EC.CN) monitoring data shows that in 2015, Chinese Mobile e-commerce market transaction was over 104 billion 600 million Yuan. The Chinese Mobile e-commerce is not only expanding in scale, but also has great potential for internal development. The relevant government of the state is also increasing its policy support, paying great attention to the development, application and popularity of mobile e-commerce. But now, Chinese Mobile e-commerce development is still faced with many problems, the lack of the security of mobile e-commerce, mobile payment defects and some problems in mobile network and so on, which can affect consumers' trust, resulting in the slow development of mobile e-commerce. Only by solving these problems, can the rapid development of mobile electronic commerce be promoted.

\section{Analysis on influence factors OF consumption confidence of College Students in mobile e-commerce}

With the popularity of mobile e-commerce in the public daily life, mobile shopping began to come within people's field of vision. As a new group in the forefront of the times, college students are keen on the network "buy" and "sell". Mobile shopping can fully meet the shopping needs of college students, but also just meet the taste of liking new things of theirs, all the advantages of shopping make college students have a strong interest in mobile shopping, mobile phone shopping has become their new concept of consumption. In the E-commerce trading activities, transaction trust has played a very important role. So, this paper mainly analyzes four main influence factors of the consumers' trust in mobile e-commerce: consumers online, businesses online, mobile technology level and mobile transaction environment.

\subsection{College students consumers factor Online}

The factor of college students' consuming become the first leading factor that affects the consumption trust of college students under the background of mobile e-commerce. First, college students' trust tendency. The tendency of trust is the degree of trust in others in the relation between people interaction. In previous studies, consumers' trust tendency has a direct impact on shopping trust, a person with a high tendency to trust is often willing to believe in others better, the reverse is true. Both Mayer and Davis believe that trust tendency affects trust relation. Second, the consumer's shopping experience online in the past. From the narrow sense, the shopping 
experience online is the customer's shopping experience in the past in a store online. From a broad sense, shopping experience online is the customer's shopping experience online over a long period of time. We can use buying frequency of shopping online to illustrate. And shopping experience online also includes the familiarity of mobile e-commerce and mobile device operating proficiency. If College students themselves are not familiar with mobile devices and are able to master mobile devices, it is difficult to complete the transaction, even distrust the mobile businesses.

\subsection{Businesses factor online}

The sellers online are the second dominant factor in mobile e-commerce trust. Business reputation, product quality, etc., are also affecting consumers' confidence. First, store reputation. The mobile Internet market is virtual, invisible, untouchable, which often causes a crisis of customers' confidence, the price of the same commodity on the mobile Internet is the same, but the customer will go to compare with which store reputation is higher, which praise rate is higher, and look through the comments that were left by the customers. The reputation is an image mark, and reputation is generally regarded as an intangible asset. A reputable mobile seller will give consumers a good sense of trust, so the reputation of the store will affect the consumers' willingness to buy. Second, product quality or service quality. Products of good quality includes product stability, user experience, reliability, performance of the product and some other aspects. And service quality is the gap between customers perception and customers expectations. Product quality and service quality will affect consumers' confidence in the purchase of businesses. Only when the product quality or service quality of the sellers on the mobile Internet is very good, will the customers not be disappointed with the sellers and be given trust and security. Third, the website design level. The level and quality of mobile website design affect the consumers' trust as well, only when the mobile website design and appearance are good, consumers can have a favorable impression on this website, allowing users to have a pleasant browsing experience.

\subsection{Mobile technology level factor}

Mobile e-commerce technology is the third leading factor affecting mobile e-commerce trust, too. First, the mobile client technology level. At present, the mobile client is already the preferred entrance of mobile shopping. "China Mobile electricity supplier data report in 2015" shows that in 2015, Chinese mobile shopping transactions online reached 842 billion 100 million Yuan, 53.6\% of mobile phone users have shopped at the mobile terminal. Through the network, more and more consumers use mobile terminals, while the convenience of mobile terminals, ease of operation, interconnection anytime anywhere and other characteristics, can access to consumers' confidence in the purchase. Second, network technology level. The quality of wireless network technology affects the consumers' trust. Currently, used wireless networks are mobile data (such as 3G, 4G) and WIFI. The faster the wireless network flows, the greater the customers' desire to buy goods. At present, college students use WIFI and mobile data, because their cost is low, which of them, a term cost of WIFI is about 100 300 Yuan per month, besides, mobile data carriers will give customers mobile data as a present. Overall, the students' shopping demands in the mobile environment can be met. Therefore, the number of college students' shopping online through wireless network is increasing. However, the current mobile technology level is not high enough, except for high price, instability, there are some other shortcomings, which also stops the mobile commerce industry in China from developing.

\subsection{Mobile transaction environment factor}

The mobile trading environment is the fourth leading factor influencing college students' consumption trust. In recent years, security issues are focused on in Chinese mobile e-commerce transaction activities. The issues of users' personal information and related privacy being divulged are extremely serious, "phishing" frauds frequently and hackers invaded the site incidents often occur. Many buyers and sellers are always skeptical about the large number of commercial activities on the web. Therefore, the Internet legal system has been improved and perfected, electronic signature legal system, electronic contract legal system came into being, they are to ensure the normal operation of mobile e-commerce, to some extent, which eliminates the concerns of businesses and consumers, increases the sense of trust. On the other hand, the emergence of third-party certification bodies, to a 
certain extent, protects the consumers in the process of transactions online in the security. In the mobile e-commerce transactions, if the security can not be guaranteed, it's difficult for consumers to have a sense of trust in mobile commerce, and even to produce exclusion.

\section{Suggestions on Promoting College Students' Consumption Trust}

\subsection{Enhance consumption confidence of College Students}

Normally, if a consumer is relatively familiar with something, it is more inclined to do so. As a result, college students' familiarity with mobile shopping will increase trust in mobile e-commerce. For example, in order to improve the college students' consuming trust in mobile e-commerce, online sellers should rev up publicity and promotion, by the way of publicity and promotion, more college students consumers will be made to know about the characteristics of mobile e-commerce. In order to let the students know how to use the mobile shopping, and master the methods of search query and identification of goods quality which mobile shopping is required for, and what's more, to make the college students understand clearly related to the laws and the E-commerce law for their rights. Now there are many online businesses setting out the their products to let the customers experience at first, to make students familiar with quality and performance of products consumed, in order to increase the consumer's shopping trust in business products, which can promote the sustainable and healthy mobile e-commerce development .

\subsection{Establish good reputation and improve the quality of website information content}

To improve college students consumers trust in mobile e-commerce sellers, firstly, establish a good corporate image and brand image, which is the business façade. So, the effective measures must be taken timely to manage the event that damages the reputation, to solve the conflict effectively between sellers and students consumers, in order to establish a good reputation. Secondly, keep promises. For businesses, never break promises for their own benefit, or businesses' reputation will be damaged. Thirdly, businesses must grow bigger and stronger. Only the enterprise is big, consumers will feel secure. Finally, businesses should also do good work on pre-sale, sale and after-sales service, which impacts on College Students consumers' confidence in the purchase of businesses directly.

In the mobile e-commerce online shopping, customers often obtain all aspects of information through visual. Therefore, consumers' requirements for the website design form and content are higher and higher. The content and information in the website must be accurate, effective and higher payment security system, the users can be provided with a secure payment environment. And what's more, consumers' personal information must be protected from leaking out, and the legitimate rights and interests of consumers must be safeguarded. Only by designing attractive web content and a secure web environment, can we increase consumers' confidence.

\subsection{Raise the level of mobile network technology}

Only by constantly strengthening the construction of mobile network technology and improving the network technology level can we increase the purchasing confidence of College students. First, for the mobile communication operators, to achieve the goal of network optimization, some problems such as not good network coverage and other issues that can not be connected in network operations should be solved, so that the network will be made to achieve the best operation state, and students consumers can connected network whenever and wherever as much as possible. Secondly, mobile operators can speed up and decrease the cost of mobile networks, so that college students can surf the Internet without hindrance, at the same time, college students can have a good shopping experience. In addition, the real name system of mobile network should be built up to make the network management develop toward to the real name system, in order that a reassuring shopping environment can be created for the groups of college students consumers.

3.4 Improve relevant e-commerce laws and regulations, step up the government for protection of the consumers' interests

Whether the laws and regulations of mobile e-commerce are perfect or not, which has a great influence on the college students' trust. Therefore, in order to enhance students consumers' trust in 
mobile commerce, first of all, the government should improve and perfect the present system of electronic commerce laws and regulations, and give college students consumers a lot of publicity, so that buyers and sellers know more about information of the laws and regulations. Secondly, strengthen the government for protection of students consumers' rights and interests. The relevant government supervision departments should severely punish the mobile e-commerce businesses that damage the consumers' rights and interests, leak any consumers' personal information or privacy without permission from consumers, businesses, to provide a safe and reliable shopping environment for college students consumers in the mobile e-commerce. At the same time, the website should comply with the laws and regulations formulated by the government, and actively expose the businesses’ illegal behaviors, and consciously accept consumers’ supervision.

\section{Conclusion}

The rapid development of mobile e-commerce has attracted the attention of academia and industry. Whether it is on the academic research of mobile commerce or the practical application of industry, they are both developing rapidly. As a business pattern, the most important purpose is to promote the development of business through research and applications, which makes it more mature. Therefore, it is very important to study the influence factors of college students consumers' trust in mobile shopping and promote the development of mobile commerce. This study just only puts forward some main factors that affect the college students consumers' trust and it needs to be demonstrated through the design model in the subsequent research. This study has some reference significance to the practice and research of mobile commerce.

\section{Acknowledgments}

This work was financially supported by Curriculum Construction Project of Quanzhou Normal University: Demonstration Network Course Construction-----ERP.

\section{References}

[1] Jun Sun, Lu Xu, A Study on the Factors Affecting B2C Mobile Business Consumers' Trust, Modern Business. 11 (2013) 107-108.

[2] Hui Li, Dong Hai Guo, A Study on the Relationship between Online Shopping Experience Sharing and Impulsive Purchase Behavior - Based on Knowledge Sharing, Journal of Hebei University of Economics and Trade (Comprehensive Edition). 03 (2015) 77-80.

[3] Qing Ting Zhou, Analysis on the Influencing Factors of B2C E - commerce Consumers' Trust, Business Age. 11 (2013) 107-108.

[4] Wei Liao Liao, Xu Hua $\mathrm{Xu}$, Analysis and Empirical Study of factors influencing consumer purchasing behavior in mobile e-commerce, Reform and Strategy.08 (2016) 113-118. 